\author{
Janusz KOGUT ${ }^{1}$ \\ Lidia BUDA-OŻÓG ${ }^{2}$ \\ Wanda KOKOSZKA ${ }^{3}$ \\ Izabela SKRZYPCZAK ${ }^{4}$
}

\title{
O MOŻLIWOŚCIACH WZMACNIANIA MOSTÓW PŁYTOWO BELKOWYCH W ASPEKCIE PROJEKTOWANIA I REALIZACJI ROBÓT WZMOCNIENIOWYCH
}

\begin{abstract}
Dynamiczny wzrost obciążeń i intensywności ruchu na sieci drogowej powoduje konieczność wzmocnienia wielu istniejących obiektów mostowych o niewystarczających parametrach geometrycznych (ilości i szerokości pasm ruchu) oraz nośności. Modernizacje każdego obiektu inżynierskiego wymagają od osób biorących w nich udział rozwagi i wiedzy eksperckiej na każdym etapie, począwszy od projektowania kończąc na wykonawstwie. Projektowanie i realizacja tych prac staje się znakomitym polem obserwacji i zdobywania doświadczeń. Zaskakują często one splotem wydarzeń uwidaczniających, że z pozoru nieistotne czynności wykonawcze są powodem dużych trudności, a czasem nawet poważnych awarii wzmacnianych obiektów. W artykule przedstawiono problemy projektowania i realizacji wzmocnień na przykładzie remontu mostu drogowego przez rzekę Jasiołkę w województwie podkarpackim. Dla wzmacnianego obiektu przeprowadzono pomiary inwentaryzacyjne $\mathrm{i}$ oględziny oraz badania sklerometryczne i chemiczne betonu. Na podstawie otrzymanych wyników określono zakres korozji elementów konstrukcyjnych, stan ich zarysowania oraz stan elementów wyposażenia. Wyniki tych badań oraz szczątkowa dokumentacja techniczna mostu pozwoliły określić sposób jego remontu i wzmocnienia. Realizacja wspomnianych robót dla tego obiektu unaoczniła problemy związane z projektowaniem i realizacją tego typu prac dla żelbetowych płytowo-belkowych obiektów mostowych.
\end{abstract}

Słowa kluczowe: projektowanie, wzmacnianie, beton, most

\footnotetext{
${ }^{1}$ Janusz Kogut, Politechnika Krakowska, ul. Warszawska 24, 31-155 Kraków, jkogut@pk.edu.pl ${ }^{2}$ Lidia Buda-Ożóg, Politechnika Rzeszowska, ul. Poznańska 2,35-211 Rzeszów, lida@prz.edu.pl ${ }^{3}$ Wanda Kokoszka, Politechnika Rzeszowska, ul. Poznańska 2, 35-211 Rzeszów, wandak@prz.edu.pl

${ }^{4}$ Autor do korespondencji: Izabela Skrzypczak, Politechnika Rzeszowska, ul. Poznańska 2, 35-211 Rzeszów,izas@prz.edu.pl
} 


\section{Wstęp}

W ostatnich latach obserwuje się dynamiczny wzrost obciążeń i zarazem większe natężenie ruchu na drogach krajowych, powiatowych i gminnych. Ta intensyfikacja użytkowania sieci drogowej generuje konieczność wzmacniania wielu istniejących obiektów mostowych, których nośność oraz parametry geometryczne (ilość i szerokości pasm ruchu) są w obecnych warunkach niewystarczające.

Dotyczy to w szczególności mostów żelbetowych płytowo-belkowych, zbudowanych u schyłku lat sześćdziesiątych. W obiektach tych obserwuje się oprócz wymienionych wyżej mankamentów - daleko posuniętą degradację elementów konstrukcyjnych i wyposażenia, spowodowaną czynnikami eksploatacyjnymi i utrzymaniowymi. Klasycznym tego przykładem był most przez rzekę Jasiołkę $\mathrm{w}$ województwie podkarpackim, stanowiący ważny element miejskiej infrastruktury transportu i komunikacji. Dlatego koniecznym stało się przeprowadzenie jego modernizacji.

\section{Określenie parametrów projektowych mostu}

\subsection{Inwentaryzacja i badania mostu}

Wzmacniany obiekt mostowy miał trzy przęsła żelbetowe płytowobelkowe. Rozpiętości teoretyczne przęseł wynosiły $14.70+21.00+14.70 \mathrm{~m}$ Zawierał 4 belki o zmiennej wysokości. Szerokość użytkowa mostu wynosiła: jezdni - $6.00 \mathrm{~m}$, obustronnych chodników- po $2.50 \mathrm{~m}$ [8].

Przekrój poprzeczny obiektu wraz z legendą przedstawiono na rysunku 1.

Dla wzmacnianego obiektu przeprowadzono szczegółowe pomiary inwentaryzacyjne i oględziny mostu oraz badania sklerometryczne i chemiczne betonu [3]. Na podstawie otrzymanych wyników badań określono zakres korozji elementów konstrukcyjnych, stan ich zarysowania oraz stan elementów wyposażenia. Wyniki badań oraz szczątkowa dokumentacja techniczna mostu pozwoliły określić sposób jego remontu i wzmocnienia. 


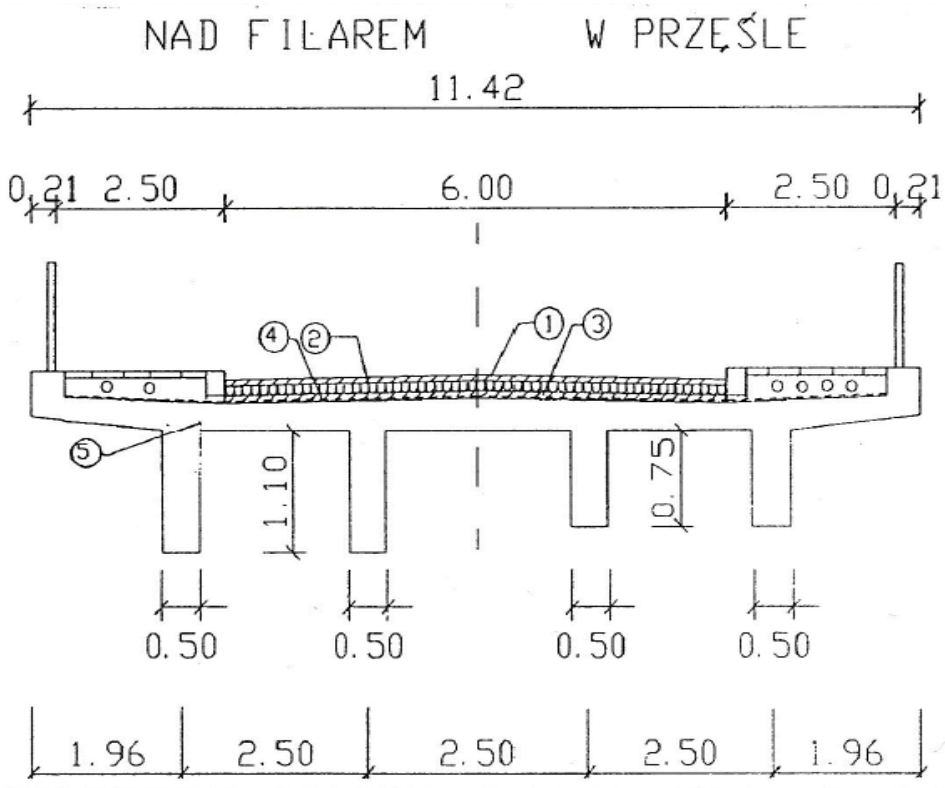

Legenda: 1- beton asfaltowy, 2 - kostka kamienna, 3 - beton ochronny, 4 - izolacja, 5 - ustrój nośny płytowo-belkowy

Rys. 1. Przekrój poprzeczny mostu przed modernizacją

Fig. 1 . The cross-section of the bridge before the modernization

\subsection{Przebieg próbnego obciążenia}

Zaproponowano tradycyjny model wzmocnienia mostu przez pogrubienie 14-to centymetrowej płyty pomostu zespolonym z nią nadbetonem o grubości od 12 do $19 \mathrm{~cm}$. Zmienna grubość nadbetonu wynikła z konieczności ukształtowania zalecanych spadków mostu, poprzecznego i podłużnego, oraz zachowania niwelety obiektu - w pionowym łuku wypukłym. Projekt modernizacji mostu objął także remont stref przypodporowych dwóch belek wraz z przyległą do nich częścią płyty, remont poprzecznic końcowych, wymianę łożysk stalowych, a także powierzchniowe uzupełnienia oraz zabezpieczenia płyty i belek. Ponieważ stan podpór nie budził zastrzeżeń zalecono jedynie powierzchniowe zabezpieczenie ich przed korozją. Ostatecznie, w uzgodnieniu $\mathrm{z}$ inwestorem przyjęto w koncepcji programowej modernizacji mostu następujące parametry:

- szerokość jezdni

$-7,0 \mathrm{~m}$

- szerokość chodników dla pieszych

$-2 \times 2,0 \mathrm{~m}$

- szerokość całkowita

$-\mathrm{B}_{\mathrm{L}}=11.40 \mathrm{~m}$

- rozpiętości teoretyczne przęseł

- $\mathrm{L}_{\mathrm{t}}=14,70+21,00+14,70 \mathrm{~m}$

- klasa obciążeń obiektu

- B wg. PN - 85/S - 10030 [1] 
- wyposażenie i konstrukcje podwieszeń urządzeń obcych - typowe dla obiektów miejskich o ruchu ciężkich pojazdów;

- konieczny warunek: remont przy utrzymaniu ruchu na połowie jezdni;

- dojazdy do mostu: płynne połączenie niwelety jezdni na moście $z$ niweletami na dojazdach do niego.

Respektując wszystkie powyższe założenia opracowano projekt remontu mostu zgodnie zaleceniami [1-7].

Zaprojektowany wzmocniony przekrój poprzeczny przedstawiono rys. 2.

Prace remontowe zrealizował wykonawca wyłoniony w trybie konkursu.

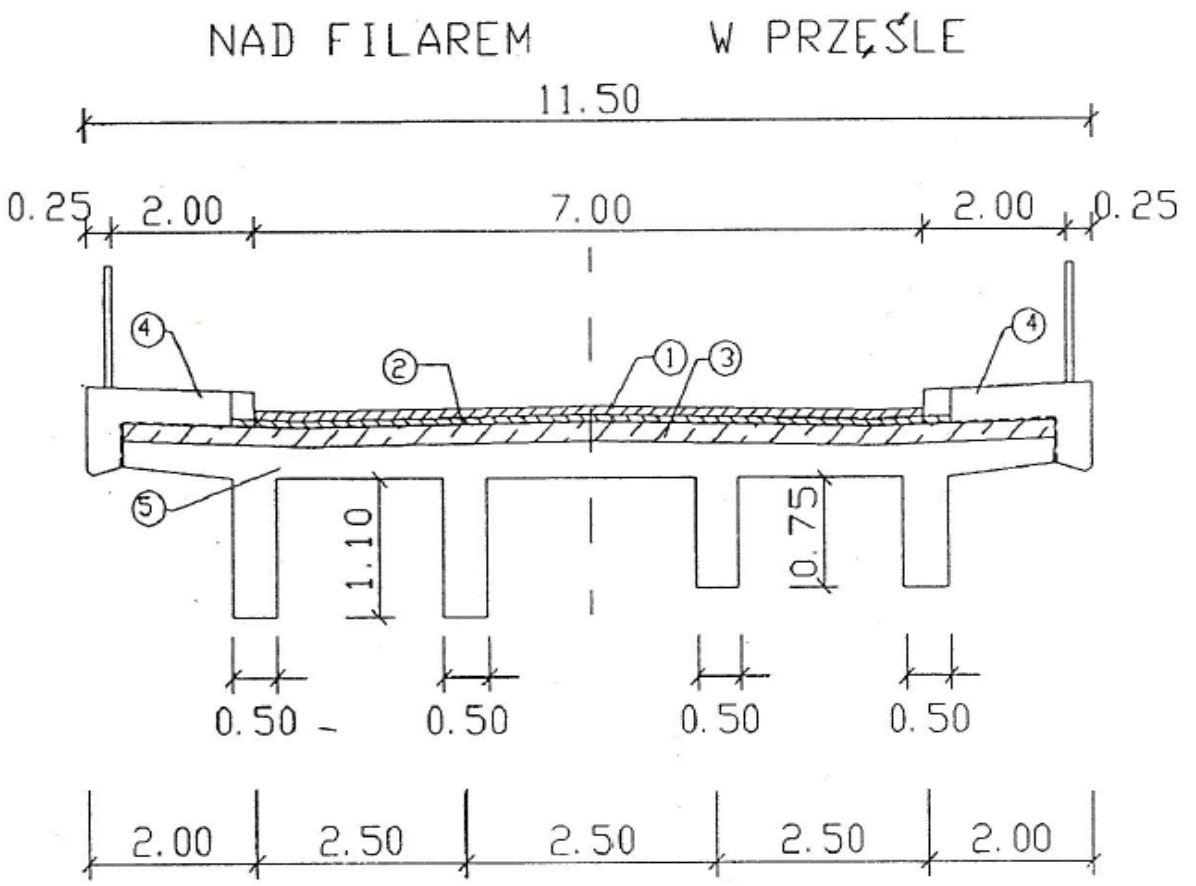

Legenda: 1 - warstwy nawierzchniowe, 2 - izolacje, 3 - nadbeton zbrojony, 4 - kapy chodnikowe, 4 - ustrój nośny płytowo-belkowy

Rys. 2. Przekrój poprzeczny mostu po modernizacji

Fig. 2. The cross-section of the bridge after modernization

\section{Prace remontowe i modernizacyjne}

Remont mostu rozpoczęto od demontażu wyposażenia połowy obiektu i rozbiórki jednego chodnika, w późnych miesiącach letnich. Pierwszym etapem prac wykonawczych było usunięcie z jezdni kostki kamiennej betonu ochronnego, izolacji z papy, a z chodnika - betonowych płytek chodnikowych, wypełnie- 
nia $\mathrm{z}$ betonu żużlowego oraz dwóch przewodów Ø $150 \mathrm{~mm}$ czynnego gazociągu średnioprężnego. Gazociąg był bez rur osłonowych, co świadczyło o niefrasobliwości służb drogowych i komunalnych. Odsłonięcie płyty pomostu umożliwiło sprawdzenie geometrii pomostu. Pomiary potwierdziły przyjęte wymiary obiektu w planie, natomiast rzędne niwelety wierzchu płyty odbiegały od rzędnych projektowych. Stwierdzono znaczne obniżenie płyty w przęśle środkowym co, aby utrzymać niweletę według łuku pionowego wymagało pogrubienia nadbetonu do ok. $23 \mathrm{~cm}$. Konieczność tak znacznego zwiększenia jego grubości a przez to ciężaru własnego konstrukcji, wywołała wątpliwości czy będzie możliwe utrzymanie klasy obciążenia B. Ponowne obliczenia statycznowytrzymałościowe potwierdziły te wątpliwości. Dlatego ostatecznie zdecydowano, iż obiekt po remoncie będzie dostosowany do przejmowania obciążeń klasy C. Po tej decyzji remont połowy mostu przebiegł sprawnie, nie nastręczając większych trudności, z wyjątkiem jednej. Była nią niemożność oczyszczenia szczelin dylatacyjnych między poprzecznicami końcowymi i ściankami nisz łożyskowych przyczółków, spowodowana wysokimi temperaturami. Szerokość szczelin wynosiła $5 \mathrm{~cm}$.

Wznowione prace po przerwie zimowej na drugiej połowie obiektu wydawały się ze względu na ich powtarzalność, że będą bardzo łatwe. Rozpoczęto od oczyszczenia pompą wodną szczelin między poprzecznicami a ściankami przyczółków. Wtedy zauważono nad filarami na powierzchniach gzymsów kap chodnikowych rysy pionowe szerokości $0.2 \mathrm{~mm}$. Naszym zdaniem świadczyło to o dwóch zjawiskach:

- konstrukcje przęseł wskutek niemożności swobodnego przesuwania się przy rozszerzeniach termicznych (wypełnione szczeliny dylatacyjne) pracowały jako częściowo sprężone, w takich warunkach wykonano kapy chodnikowe.

- oczyszczenie dylatacji umożliwiło swobodny przesuw konstrukcji, a przez to spowodowało jej rozprężenie, co stało się przyczyną ogromnej koncentracji naprężeń w dole gzymsów kap chodnikowych, znacznie przekraczających wytrzymałość betonu na rozciąganie.

Te zjawiska były prawdopodobnie przyczyną powstania rys. Aby ich uniknąć zastosowano w drugiej połowie mostu, nad filarami, pozorne zdylatowanie kapy chodnikowej, paskami cienkiej płyty pilśniowej.

Kolejnym etapem prac była wymiana na przyczółkach stalowych łożysk wałkowych na łożyska elastomerowe. Wymagało to podniesienia w dwóch etapach przęseł skrajnych, uwolnienia istniejących łożysk i zainstalowanie nowych. Wówczas pojawiły się na dwóch belkach pionowe rysy o rozwartości 0.2 do $0.4 \mathrm{~mm}$, niestwierdzone $\mathrm{w}$ trakcie inwentaryzacji mostu. Analiza zastosowanego sposobu podnoszenia belek nasunęla wątpliwości, czy wykonawca robót dotrzymał warunków i zaleceń podanych w projekcie tj. czy nie przekroczył wyznaczonych wartości podniesienia wynoszącej $3 \mathrm{~mm}$. Groziło to zniszczeniem przęseł skrajnych. Pomiary sprawdzające wykazały, 
że w rzeczywistości końce belek podniesiono $17 \mathrm{~mm}$. Po opuszczeniu konstrukcji do poziomu projektowego - rysy zamknęły się. Wnioski z zaistniałej sytuacji są oczywiste. Konstrukcja przęsła poddana obciążeniu użytkowemu na połowie jezdni, a więc działającemu mimośrodowo obciążeniu użytkowemu na połowie jezdni, konstrukcja dodatkowo została przeciążona wskutek nadmiernego przemieszczenia pionowego (podniesienie końców belek). Sumaryczne obciążenie spowodowało duże dodatkowe naprężenia skręcające belek i stad pojawienie się rys. Wymiana łożysk niekoniecznie wymaga podniesienia przęsła. Postępowaniem bezpieczniejszym z punktu widzenia statyki konstrukcji jest tymczasowe bezpośrednie podparcie na podporze konstrukcji przęsła i obniżenie łożysk. Można to zrealizować przez kolejne podwiercanie betonu pod dolnymi płytami łożysk, powodujące ich obniżenie, co w efekcie umożliwia ich wymianę. O słuszności takiego sposobu wymiany łożysk świadczy przykład remontu Mostu Cłowego w Szczecinie, w którym tak wykonana wymiana łożysk na przyczółku zapewniła ciągłość nie tylko ruchu na obiekcie, ale i ciągłość robót remontowych (rozwiązanie zaproponowane przez prof. A. Jarominiaka z Zakładu Dróg i Mostów PRz.). Należy podkreślić, że skręcanie jako czynnik powodujący wytężenie konstrukcji jest często traktowany w projektowaniu marginalnie. Zastosowanie zbrojenia ze względu na skręcanie jest rzadko stosowane, co wydaje się podejściem wielce ryzykownym.

Kolejne etapy prac modernizacyjnych przebiegły bez zakłóceń, co pozwoliło uzyskać most o założonych cechach użytkowych i estetycznych.

\section{Uwagi końcowe}

Remont i modernizacja każdego obiektu inżynierskiego wymagają od osób biorących w nich udział rozwagi i inwencji na każdym etapie tego przedsięwzięcia, począwszy od projektowania kończąc na wykonawstwie. Projektowanie i realizacja robót wzmocnieniowych stają się znakomitym polem obserwacji i zdobywania doświadczeń. Zaskakują one często splotem wydarzeń uwidaczniających, że z pozoru nieistotne czynności wykonawcze są powodem dużych trudności, a czasem nawet poważnych awarii wzmacnianych obiektów. Problemy te można było zaobserwować na przykładzie przedstawionego w artykule remontu mostu przez rzekę Jasiołkę.

\section{Literatura}

[1] PN-85/S-10030 Obiekty mostowe. Obciążenia

[2] PN-91/S-10042. Obiekty mostowe. Konstrukcje betonowe, żelbetowe i sprężone

[3] PN-77/S-10040. Żelbetowe i betonowe konstrukcje mostowe. Wymagania i badania

[4] Czerski Z., Pajchel W.: Mosty żelbetowe, WKŁ, Warszawa 1969

[5] Jarominiak A.: Przeglądy obiektów mostowych, WKŁ, Warszawa 1991 
[6] Muczko A., Stefański E.: Modernizacja i naprawa mostów żelbetowych, WKŁ, Warszawa 1981

[7] Rybak M.: Przebudowa i wzmacnianie mostów, WKŁ, Warszawa 1983

[8] Projekt budowlany i wykonawczy modernizacji mostu przez rzekę Jasiołkę

\title{
ON DESIGN AND IMPLEMENTATION OF STRENGTHENING OF THE CONCRETE SLAB-BEAM BRIDGES
}

\begin{abstract}
S u m m a r y
A significant increase in the burden and the amount of traffic on the road network need to strengthen many existing bridges with insufficient geometrical parameters (the number and width of traffic lanes) and their load capacity. Modernization of each and every engineering structure requires from the participating in them engineers prudence and expertised knowledge at every stage of works, from initial design to workmanship details. Design and implementation of these works is an excellent field of observation and gaining of experience. Surprisingly, they often show the tangle of events that seemingly insignificant enforcement action are the cause of great difficulties, and sometimes even serious accidents of strengthened structures. The paper presents selected problems of design and implementation of reinforcements during the renovation of a road bridge over the river Jasiołka in Podkarpackie Voivodship. Visual inspection and the inventory measurements has been performed for strengthed bridge, as well as sclerometric tests of compressive strength and chemical testing of concrete. Based on the obtained results, the range of corrosion of structural elements, their cracks and the condition of the equipment have been determined. The results of these studies and rudimentary bridge technical documentation allowed to determine the range of renovation and strengthening. Application of these works for this structure revealed problems related to the design and implementation of such strengthening procedure for concrete slab-beam bridges.
\end{abstract}

Keywords: design, strengthening, concrete, bridges

Przesłano do redakcji:30.05.2015

Przyjęto do druku:10.01.2016

DOI: $10.7862 /$ rb.2015.190 